\title{
Investigation of $6-\left[{ }^{18} \mathrm{~F}\right]-$ Fluoromaltose as a Novel PET Tracer for Imaging Bacterial Infection
}

\section{Gayatri Gowrishankar ${ }^{1}$, Mohammad Namavari ${ }^{1}$, Erwan Benjamin Jouannot ${ }^{2}$, Aileen Hoehne ${ }^{1}$, Robert Reeves ${ }^{1}$, Jonathan Hardy ${ }^{3}$, Sanjiv Sam Gambhir ${ }^{1,4 *}$}

1 Department of Radiology, Stanford University School of Medicine, Stanford, California, United States of America, 2 Sanofi R\&D, Sanofi, Paris, France, 3 Department of Pediatrics, Stanford University School of Medicine, Stanford, California, United States of America, 4 Department of Bioengineering, Stanford University School of Medicine, Stanford, California, United States of America

\begin{abstract}
Despite advances in the field of nuclear medicine, the imaging of bacterial infections has remained a challenge. The existing reagents suffer from poor sensitivity and specificity. In this study we investigate the potential of a novel PET (positron emission tomography) tracer that overcomes these limitations.
\end{abstract}

Methods: $6-\left[{ }^{18} \mathrm{~F}\right]$-fluoromaltose was synthesized. Its behavior in vitro was evaluated in bacterial and mammalian cultures. Detailed pharmacokinetic and biodistribution profiles for the tracer were obtained from a murine model.

Results: $6-\left[{ }^{18} \mathrm{~F}\right]$-fluoromaltose is taken up by multiple strains of pathogenic bacteria. It is not taken up by mammalian cancer cell lines. 6-[ $\left.{ }^{18} \mathrm{~F}\right]$-fluoromaltose is retained in infected muscles in a murine model of bacterial myositis. It does not accumulate in inflamed tissue.

Conclusion: We have shown that $6-\left[{ }^{18} \mathrm{~F}\right]$-fluoromaltose can be used to image bacterial infection in vivo with high specificity. We believe that this class of agents will have a significant impact on the clinical management of patients. Citation: Gowrishankar G, Namavari M, Jouannot EB, Hoehne A, Reeves R, et al. (2014) Investigation of 6-[ ${ }^{18}$ F]-Fluoromaltose as a Novel PET Tracer for Imaging
Bacterial Infection. PLoS ONE 9(9): e107951. doi:10.1371/journal.pone.0107951

Editor: Kewei Chen, Banner Alzheimer's Institute, United States of America

Received June 12, 2014; Accepted August 17, 2014; Published September 22, 2014

Copyright: (C) 2014 Gowrishankar et al. This is an open-access article distributed under the terms of the Creative Commons Attribution License, which permits unrestricted use, distribution, and reproduction in any medium, provided the original author and source are credited.

Data Availability: The authors confirm that all data underlying the findings are fully available without restriction. All relevant data are within the paper and its Supporting information files.

Funding: The authors received no specific funding for this work.

Competing Interests: The authors have a patent on the imaging probe described in the manuscript. Patent title: PROBES AND METHODS OF IMAGING A BACTERIAL INFECTION. Serial No. 14/204,402. Filed: March 11, 2014. Docket No. 221907-1950. One of the authors, Dr. Erwan Jouannot, is an employee of Sanofi Inc. This does not alter the authors' adherence to PLOS ONE editorial policies and criteria. Sanjiv Sam Gambhir is on the editorial board for PLOS ONE. This does not alter the authors' adherence to PLOS ONE editorial policies and criteria.

* Email: gayatrig@stanford.edu

\section{Introduction}

The incidence of bacterial infections in hospitals worldwide has been on the rise, particularly with the emergence of several strains of resistant pathogenic bacteria (e.g., methicillin-resistant Staphylococcus aureus, multidrug-resistant Streptococcus pneumoniae, Clostridium difficile, etc.). It is estimated that one out of every 25 hospitalized patients in the United States will suffer from a health care associated infection (HAI) (source: center for disease control, CDC). The CDC estimates that there were an estimated 722,000 HAI in American hospitals in 2011. 72,000 of these patients died as a direct result of these infections. Positive culture from the suspected sites (tissue and/or blood) is the current gold standard in the diagnosis of bacterial infection. This method suffers from some limitations: a) it is invasive, b) it is unable to determine spread of infection and c) the time it takes to obtain results can often result in a fatality. There have been several attempts to image bacterial infection both pre-clinically and clinically summarized in recent reviews [1-5]. Most of the pre-clinical work was based on optical imaging using bioluminescent strains of bacteria and fluorescent probes [6-9]. These studies have been valuable to medical microbiology and have helped understand several aspects of bacterial colonization, spread and susceptibility to available treatment methods. However these methods are not yet amenable to clinical translation. Clinically there have been several PET and SPECT tracers tested $[1,2,4,10]$. The most promising of these was the study by Diaz et al using positron emission tomography (PET) and $1-2$-deoxy-2'-fluoro- $\beta$-D-arabinofuranosyl)-5- $\left[{ }^{124} \mathrm{I}\right]$ iodouracil (FIAU), to identify bacterial lesions in patients with suspected musculoskeletal infections [11]. The main limitation of this study is the fact that FIAU is a substrate of the bacterial enzyme-thymidine kinase but also for the mammalian mitochondrial thymidine kinase, leading to an increased background imaging signal in certain tissues. Others have shown that FIAU may not be taken up by all strains of bacteria [12] including Pseduomonas aeruginosa which is responsible for 51,000 of all nosocomial infections in the USA every year. Despite the multitude of imaging agents that have been developed for infection over the last decade, there is no single probe that is able to image all classes of bacteria. For eg. ${ }^{99 \mathrm{~m}} \mathrm{Tc}-$ Labeled antimicrobial peptide ubiquicidin $\left(29^{\text {th }}\right.$ amino acid- $41^{\text {th }}$ amino acid) accumulates less in Escherichia coli infection than in Staphlococcus aureus infection [13]. There is therefore a need to 
develop a probe that would be able to image infections caused by all classes of bacteria to minimize false negatives. In a recent study, Murthy et al. have demonstrated the use of fluorescent maltodextrin-based probes to image bacteria in pre-clinical models with a high degree of specificity and sensitivity [14]. Maltose and maltodextrins appear to be used as energy sources exclusively by bacteria. All species of bacteria including pathogenic strains express a series of genes (commonly known as the maltodextrin transport complex) that accomplish the binding, transport and utilization of maltose and maltodextrin [15-17]. This transport mechanism is absent in mammalian cells, making maltose a substrate unique to bacteria and hence a promising choice to build imaging probes directed specifically against bacteria. PET is the most relevant imaging modality for detection of molecular signatures in the clinic because it allows whole body imaging with a sensitivity of $10^{-12} \mathrm{M}$ and a high spatial resolution of $\sim 5 \mathrm{~mm}$ [18]. Here, we examine the use of a maltose based PET agent to image bacteria in cell culture and in vivo.

\section{Materials and Methods}

\section{Synthesis}

4-O-( $\alpha$-D-glucopyranosyl)-6-deoxy-6- $\left[{ }^{18} \mathrm{~F}\right]$ fluoro-D-glucopyranoside $\left(6-\left[{ }^{18} \mathrm{~F}\right]\right.$ fluoromaltose) was prepared by nucleophilic displacement of the nosylate group in a 1,2,3-tri-O-acetyl-4-O- $\left(2^{\prime}, 3^{\prime}\right.$,-di-O-acetyl-4', $6^{\prime}$ benzylidene- $\alpha$-D-glucopyranosyl)-6-deoxy-6-nosyl-D-glucopranoside precursor by $\left[{ }^{18} \mathrm{~F}\right]$ fluoride ion in acetonitrile at $80^{\circ} \mathrm{C}$ for $10 \mathrm{~min}$. Initial purification of the ${ }^{18} \mathrm{~F}$-labeled protected intermediate was performed via a light C-18 Sep-Pak cartridge. After passing the solution of the ${ }^{18} \mathrm{~F}$-labeled intermediate in acetonitrile through a light neutral alumina Sep-Pak, it was evaporated to dryness and deprotection was carried out first with $1 \mathrm{~N} \mathrm{HCl}$ $\left(110^{\circ} \mathrm{C}, 10 \mathrm{~min}\right)$ followed by $2 \mathrm{~N} \mathrm{NaOH}$ at room temperature for $4 \mathrm{~min}$. After neutralization and HPLC purification of the solution, $6-\left[{ }^{18} \mathrm{~F}\right]$ fluoromaltose was recovered in 5-8\% radiochemical yield (decay corrected) with 95\% radiochemical purity. Additional details are available in a related manuscript [19].

\section{Cultures}

The E.coli strain was obtained from American Type Culture Collections (ATCG 33456). The bioluminescent strain of Pseudomonas aeruginosa (Xen 5) and the Listeria monocytogenes strain (Xen 32) were obtained from Perkin Elmer. The mammalian cell lines MDA MB231 (breast cancer cell line), HeLa (cervical carcinoma cell line), J774 (murine macrophage cell line) and EL4 (murine lymphoma cell line), originated from ATCC and were grown in media recommended by ATCG.

\section{Bacterial uptake studies}

An overnight $(\mathrm{O} / \mathrm{N})$ culture of the respective strain of bacteria was initiated by inoculating a colony from a plate into a $3 \mathrm{ml}$ culture of LB broth. The next morning, $500 \mu \mathrm{l}$ of the $\mathrm{O} / \mathrm{N}$ culture was inoculated into $30 \mathrm{ml}$ of LB in a $200 \mathrm{ml}$ flask and grown in a $37^{\circ} \mathrm{C}$ shaker/incubator until the bacterial culture reached $\log$ phase $\left(\mathrm{OD}_{600}=0.5\right)$. Aliquots of $10^{8}$ colony-forming units $(\mathrm{CFU})$ of the bacterial culture were incubated with the tracer for the designated periods. At the end of the incubation period, unbound tracer was removed by washing and the cultures were lysed using a bacterial lysis solution (BugBuster, EMD, Billerica MA USA). The counts associated with the lysate were determined using a gamma counter. The protein concentration in the lysate was determined using standard methods (Pierce, Thermo Fisher Scientific, Rockford IL, USA). All samples were compared to total activity references and the percentage uptake per microgram protein was calculated.

\section{E.coli induced murine myositis}

6-7 week old nude mice $(n=15)$ were anesthetized by isoflurane inhalation. $5 \times 10^{7} \mathrm{CFU}$ of a specific strain of E.coli (ATCC 33456 ) in $50 \mu \mathrm{l}$ of LB broth was administered as an intra-muscular injection, into the right thigh of the mice. The mice were imaged $24 \mathrm{~h}$ after the initial infection.

\section{Heat inactivation of $E$. coli}

An $\mathrm{O} / \mathrm{N}$ culture of a bioluminescent strain of E.coli (Top10 harboring a plasmid encoding the lux operon) was set up as described above and allowed to reach log phase. Aliquots of the culture containing $10^{8} \mathrm{CFU}$ of bacteria were heat inactivated at $90^{\circ} \mathrm{C}$ for 30 minutes and then implanted in the left thigh of nude mice $(n=3)$. An equal number of viable bacteria were implanted in the contralateral thigh by intra-muscular injection. 1 hour later the mice were imaged on the IVIS-200 (for bioluminescence) and micro PET/CT.

\section{Turpentine oil induced sterile abscess model}

6-7 week old BALB/c mice $(n=3)$ were anesthetized by isoflurane inhalation. $30 \mu \mathrm{l}$ of turpentine oil (Sigma) was administered intra-muscularly into the right thigh of the mice. The contralateral muscle, which received no treatment, was used as controls. The mice were imaged by micro PET/CT at $72 \mathrm{~h}$ post induction of inflammation. The mice were sacrificed at the end of the study for biodistribution analysis.

\section{Micro PET/CT}

$7.4 \mathrm{MBq}$ of the radiotracer was administered to the mice intravenously. The mice were kept anesthetized with isoflurane after tracer administration. At the desired times, the mice were placed on the bed of the micro PET/CT scanner (Inveon, Siemens, Germany) and 5 min static scans were performed. For the dynamic scans, tail vein catheters $(12 \mathrm{~cm}$ PU tubing and $27 \mathrm{~g}$ butterfly needle) were inserted into the tail vein of the mice and the catheter was glued onto the tail using Vet Bond (tissue glue). Once the animal was in position in the PET part of the PET/CT scanner, $7.4 \mathrm{MBq}$ of the tracer was administered via the catheter and the PET scan was started. The dynamic scan was performed for an hour. During the scan special precautions were taken to make sure the mice were warm. All images were reconstructed using 3D-OSEM. Region of interest (ROI) analysis were done using IRW software (Inveon Research Workplace, Siemens, Germany).

\section{Biodistribution Studies}

$7.4 \mathrm{MBq}$ of the radiotracer was administered to the mice intravenously. The mice were kept anesthetized after tracer administration. At the desired time after tracer injection, the mice were sacrificed by cervical dislocation. Then relevant organs/ tissues were removed, placed in gamma counter tubes and weighed. Tissue-associated radioactivity was determined in a gamma counter (Cobra, Perkin Elmer, Waltham MA USA), decay-corrected to time of tracer injection and normalized to total injected activity using diluted aliquots of the initial administered dose as standards.

\section{Histology}

The tissues were collected in formalin, embedded in paraffin and processed. Gram staining and Hematoxlin \& Eosin (H\&E) staining of the muscle sections was performed using standard protocols. 


\section{Statistics}

Unpaired t test was performed to compare differences between control and treated groups using Graphpad from Prism (version 6.0, La Jolla CA, USA)

\section{Ethics Statement}

All animal work was done as per guidelines set by the Stanford IACUC. The protocol number is \#9547. The work did involve use of anesthesia (isoflurane) and the animals did have to be euthanized (cervical dislocation). Both methods were approved in the animal protocol by the Stanford IACUC.

\section{Results}

\section{Cell culture studies with 6-[ $\left[{ }^{18} \mathrm{~F}\right]$-fluoromaltose}

The $6-\left[{ }^{18} \mathrm{~F}\right]$-fluoromaltose was synthesized as described in Materials and Methods [19]. Aliquots of $10^{8} \mathrm{CFU}$ of log-phase bacterial cultures (E.coli ATCG 33456, P.aeruginosa and L.monocytogenes) were incubated with $6-\left[{ }^{18} \mathrm{~F}\right]$-fluoromaltose for the indicated times (Fig 1A). The three different strains of bacteria took up the tracer, in contrast to the tumor cell lines MDA-MB231 (human breast cancer) and HeLa (human cervical cancer) which took up very low levels of tracer (Fig 1B). As another test of the specificity of the transporter, E.coli cultures were incubated with and without an excess of cold maltose- the natural substrate of the maltose transporter. The uptake of $6-\left[{ }^{18} \mathrm{~F}\right]$-fluoromaltose was blocked $95 \%(\mathrm{p}<0.05)$ in the presence of $1 \mathrm{mM}$ of cold maltose. In light of the results seen in Fig. 1A, we wanted to see if the $6-\left[{ }^{18} \mathrm{~F}\right]-$ fluoromaltose could be used to track intracellular pathogens. L.monocytogenes is a classic intracellular pathogen that infects macrophages. J774 a mouse macrophage cell line was infected with a bioluminescent strain of L.monocytogenes at a MOI of 10:1. Fig. 1C shows that the cells have been infected with a bioluminescent strain of Listeria. However, the tracer is not taken up by the Listeria within the infected macrophages (Fig. 1D).

\section{Murine studies with $6-\left[{ }^{18} \mathrm{~F}\right]$-fluoromaltose}

$5 \times 10^{7} \mathrm{CFU}$ of a bioluminescent strain of E.coli was administered into the left thigh muscle of nude mice $(n=15) .7 .4 \mathrm{MBq}$ of the $6-\left[{ }^{18} \mathrm{~F}\right]$-fluoromaltose was then administered via tail-vein. Dynamic scans were performed on some of the mice for the first 1 $\mathrm{hr}$ after tracer injection (Movie S1 and Fig. S3 in File S1). The remaining mice were scanned at $2 \mathrm{~h}(\mathrm{n}=4), 3 \mathrm{~h}(\mathrm{n}=4)$ and $4 \mathrm{~h}$ $(\mathrm{n}=4)$ after tracer injection. Fig. 2A shows a representative 3D color map from a PET/CT scan. The tracer clearly accumulates in the infected leg. ROI analysis showed that infected muscle had an average uptake of $3.5 \pm 0.6 \% \mathrm{ID} / \mathrm{g}$ (mean $\pm \mathrm{SD}$ ) at $2 \mathrm{~h}$, $4.2 \pm 0.7 \% \mathrm{ID} / \mathrm{g}$ at $3 \mathrm{~h}$ and $3.6 \pm 0.7 \% \mathrm{ID} / \mathrm{g}$ (mean $\pm \mathrm{SD})$ at $4 \mathrm{~h}$ (Fig. 2G). This is 2-fold higher than the contralateral leg at all three time points and the difference is statistically significant $(\mathrm{p}<$ 0.05). The route of clearance of the tracer is predominantly renal with the bladder also clearly visualized, although there is hepatobiliary clearance as well. Fig. 2B and Fig. S3 in File S1 show the time-activity curves obtained from the dynamic scans. These show the tracer clearing from most organs including the control muscle. However in the infected muscle, the tracer accumulates over time and appears to be retained.

\section{$6-\left[{ }^{18} \mathrm{~F}\right]-$ fluoromaltose is taken up specifically in viable bacteria}

In order to confirm that $6-\left[{ }^{18} \mathrm{~F}\right]$-fluoromaltose was taken up specifically by bacteria, $10^{8} \mathrm{CFU}$ of heat inactivated bioluminescent E.coli was implanted in the right thigh of nude mice $(\mathrm{n}=3)$.
The same number of metabolically active E.coli was implanted in the contralateral thigh. $7.4 \mathrm{MBq}$ of the $6-\left[{ }^{18} \mathrm{~F}\right]$-fluoromaltose was then administered 1 hour after implantation. PET/CT images show the tracer accumulating in the leg with viable bacteria (Fig. 3A). Bioluminescence imaging of the same mice (Fig. 3B) confirm the presence of viable bacteria. ROI analysis (Fig. 3C) shows that the tracer is able to differentiate tissues bearing viable bacteria from heat-inactivated bacteria (1.3 fold, $\mathrm{p}<0.05)$.

\section{$6-\left[{ }^{18} \mathrm{~F}\right]-$ fluoromaltose is specific for bacterial infections}

In order to assess the specificity of the maltose tracer for bacterial infection, its uptake in the standard turpentine oil induced inflammation model was evaluated. Fig. 4A compares the ex vivo biodistribution of immunosuppressed nude mice bearing E.coli infection $(\mathrm{n}=3), 24 \mathrm{~h}$ after infection and immunocompetent $\mathrm{BALB} / \mathrm{c}$ mice bearing turpentine oil induced abscesses $(n=3)$ on their legs (Fig 4B), $72 \mathrm{~h}$ after induction. There is no difference in muscles bearing inflammation vs. the contralateral muscle in the $\mathrm{BALB} / \mathrm{c}$ mice. However, in the nude mice bearing the bacterial infection, there is a 2.1 fold difference in accumulation in the infected leg vs the contralateral leg, and this difference is statistically significant $(p<.05)$. These results indicate that the maltose class of tracers was specific for bacterial infection. Gram staining and $\mathrm{H} \& \mathrm{E}$ staining confirmed the presence of bacteria in infected muscles (Fig. 4G) as well as neutrophils and macrophages in the inflammation model (Fig. 4D).

\section{Discussion}

In this paper we have evaluated 6 - $\left[{ }^{18} \mathrm{~F}\right]$-fluoromaltose as a PET tracer for imaging bacterial infection. Our results in Fig. 1A show that this tracer is a specific substrate for the maltose family of transporters, and its uptake in E. coli was blocked by co-incubation with an excess of maltose. This transport system, although first identified and studied from E.coli, is present in multiple Gramnegative and Gram-positive bacterial species. It is not specific for pathogenic strains of bacteria and is present in all species of bacteria, although it has been shown to confer a survival advantage for certain pathogenic strains of bacteria [16,17]. However, this class of transporters is not known to be present in mammalian cells as mentioned in the introduction. It was shown by Murthy et al. that the fluorescent maltodextrin probes did not enter mammalian cells [14].

Fig. 1B shows that $6-\left[{ }^{18} \mathrm{~F}\right]$-fluoromaltose is also not taken up by multiple mammalian cell lines. ${ }^{3} \mathrm{H}$-maltose (American radiolabeled chemicals) was also taken up exclusively by bacteria and not by mammalian cell lines (Figure S1 in File S1). Hence this class of tracers (maltose and analogs) will likely image all bacterial strains with the exception of Listeria monocytogenes and other intracellular pathogens, which infect and colonize mammalian cells as part of their lifecycle (as shown in Fig. 1C and Fig. 1D).

In Figs. 2 and 3 the behavior of this tracer in vivo is shown. The tracer does accumulate specifically in infected muscle as shown in Figures 2A, B and $\mathrm{C}$. The tracer also accumulates only in viable, metabolically active bacteria as shown in Fig 3A albeit with a small but significant difference to the contralateral muscle. The tracer is able to pick up as little as $10^{6} \mathrm{CFU}$ of bacteria (Figure S2 in File S1), which falls within the range of the number of bacteria detected in infected tissue in a clinical setting. It does not accumulate in sites of inflammation as shown in Fig. 4B, which further demonstrates the specificity of the maltose class of probes for bacterial populations. In addition, the tracer did not accumulate in the gut microflora. However, the overall signal-tobackground ratio needs to be improved in future generations of 


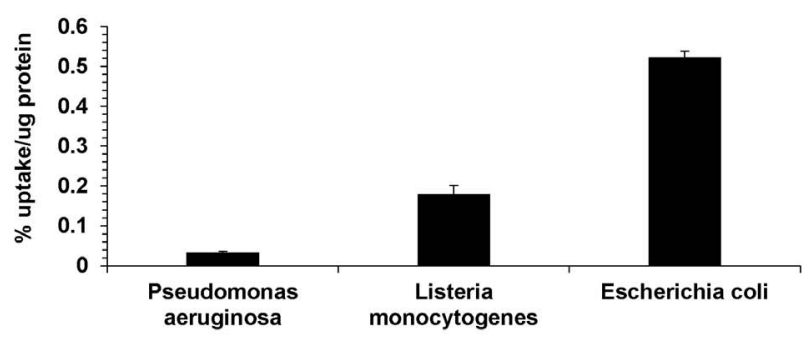

c

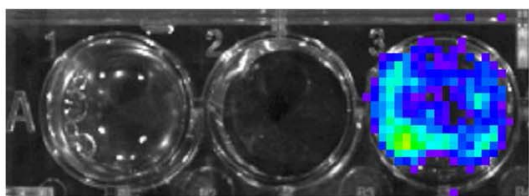

$\mathrm{J} 774$

J774 with Listeria monocytogenes

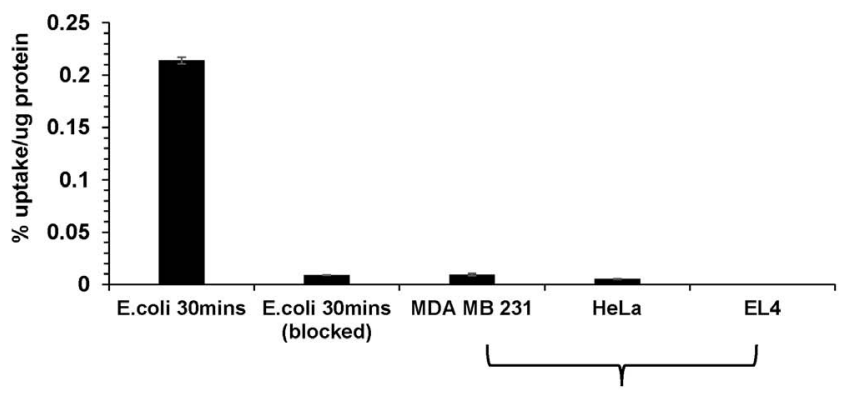

Mammalian cells
D

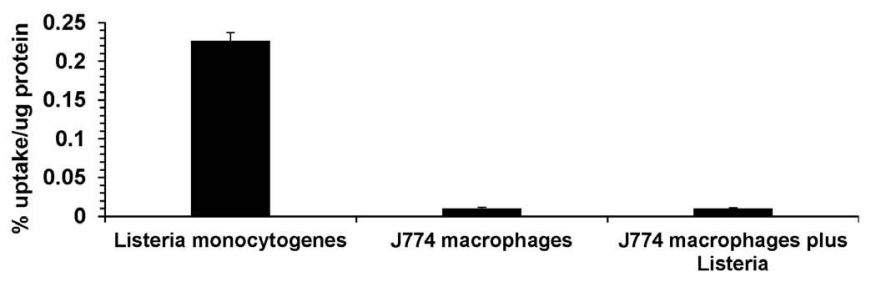

Figure 1. In vitro characterization of $6-\left[{ }^{18} \mathrm{~F}\right]$-fluoromaltose. A) Uptake of $6-\left[{ }^{18} \mathrm{~F}\right]$-fluoromaltose in the indicated strains of bacteria for 60 minutes. B) 1 hour uptake of $6-\left[{ }^{18} \mathrm{~F}\right]$-fluoromaltose in the mammalian cell lines, MDA MB231 and HeLa and its uptake in E.coli in the presence of $1 \mathrm{mM}$ maltose. C) Bioluminescence imaging of a macrophage cell line J774 infected with a bioluminescent strain of Listeria monocytogenes. D) 1 hour uptake of 6-[ $\left.{ }^{[8} \mathrm{F}\right]$-fluoromaltose in the bioluminescent strain of Listeria monocytogenes and in macrophage cell line J774 with and without intracellular Listeria infections.

doi:10.1371/journal.pone.0107951.g001

A

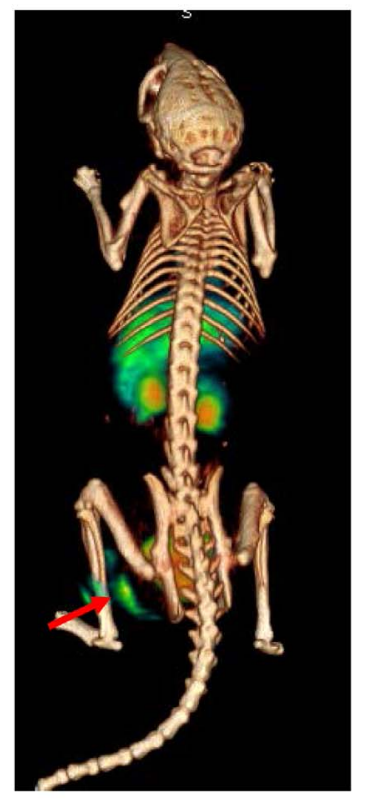

B

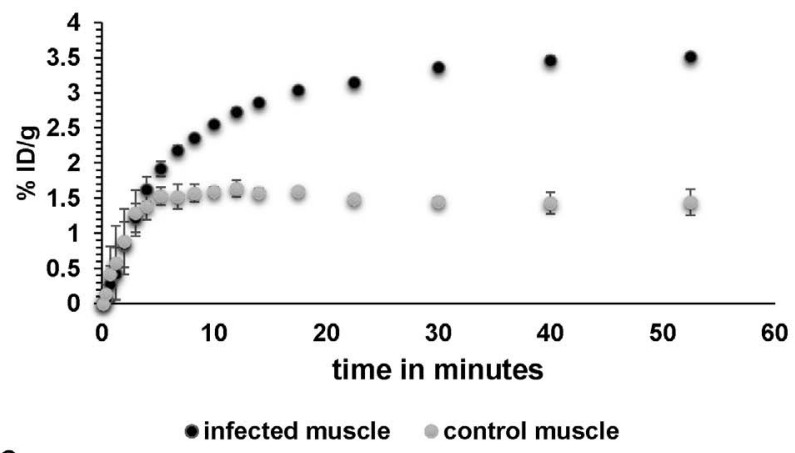

C

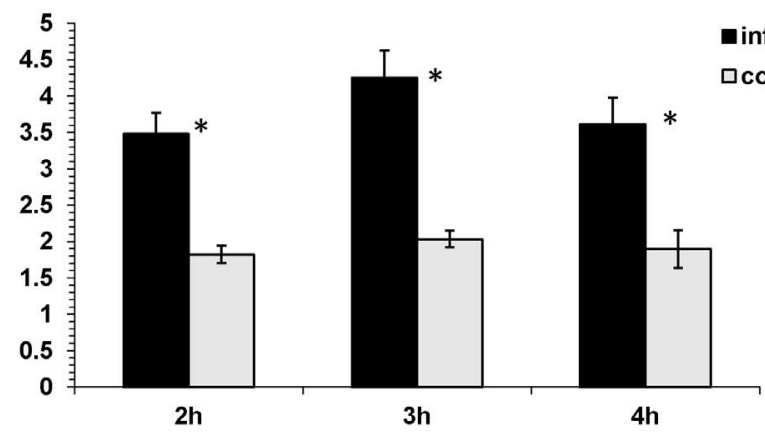

Figure 2. In vivo characterization of $6-\left[{ }^{18} \mathbf{F}\right]$-fluoromaltose. A) $3 \mathrm{D}$ color map from a PET/CT scan of a mouse bearing E.coli induced infection on the left thigh (red arrow) $1 \mathrm{hr}$ after tail-vein injection of 7.4MBq of 6- $\left[{ }^{18} \mathrm{~F}\right]$-fluoromaltose. B) Region of interest analysis (ROls) from PET/CT images at the indicated time points $\left(n=4\right.$ for each time point) ${ }^{*}$ indicates statistical significance with $p<0.05$. C) Time activity curve showing accumulation of 6 $\left[{ }^{18} \mathrm{~F}\right]$-fluoromaltose in the infected muscle $(\mathrm{n}=3)$. doi:10.1371/journal.pone.0107951.g002 

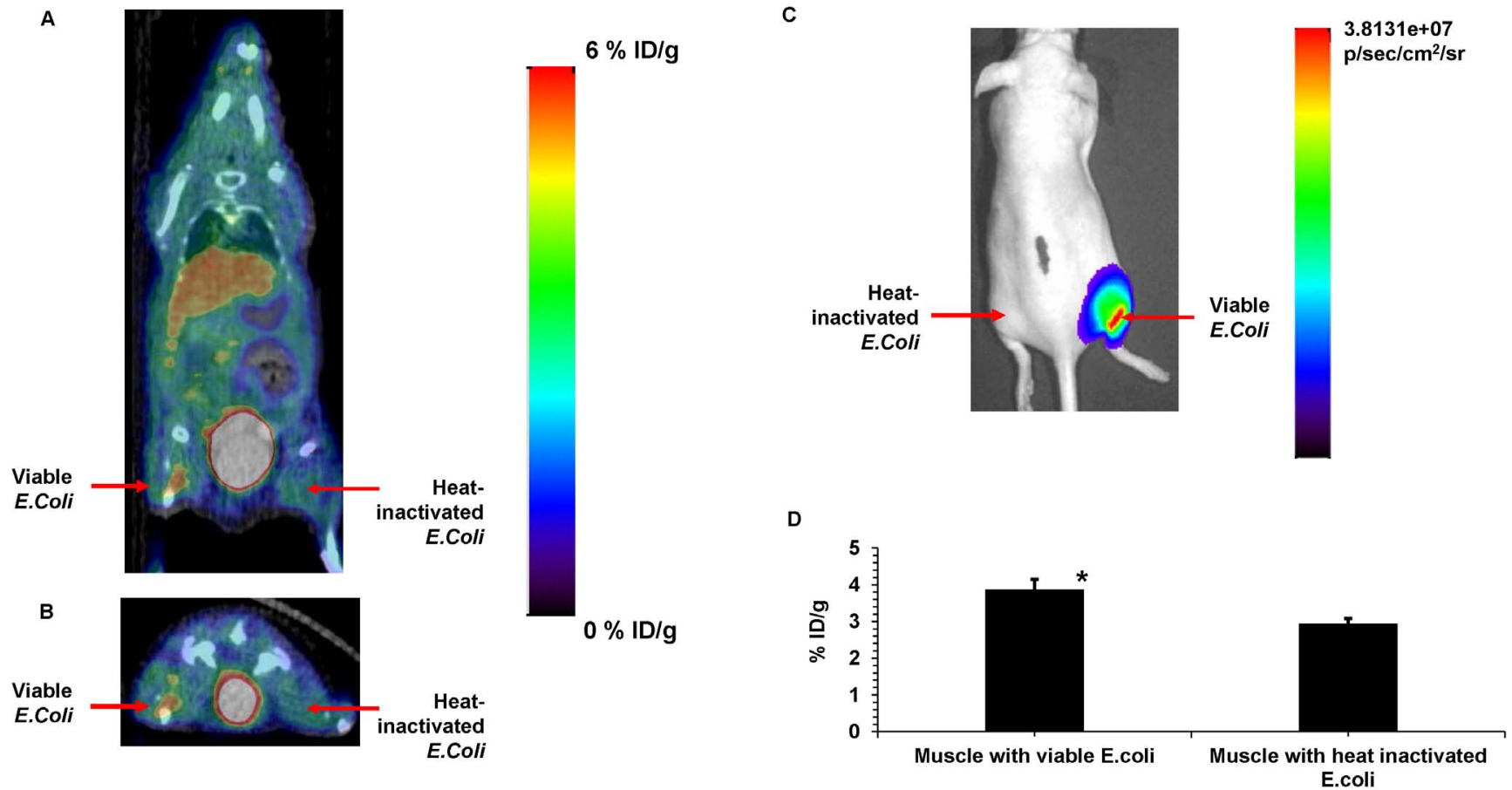

Figure 3: Specificity of 6-[ $\left.{ }^{18} \mathrm{~F}\right]$-fluoromaltose for viable bacteria. A) A coronal slice from a PET/CT image of a mouse bearing $10^{8} \mathrm{CFU}$ of viable bioluminescent E.coli on the right thigh (red arrow) and $10^{8} \mathrm{CFU}$ of heat-inactivated E.coli on the left thigh, $1 \mathrm{hr}$ after tail-vein injection of 7.4MBq of 6$\left[{ }^{18} \mathrm{~F}\right]$-fluoromaltose B) A transverse slice from the same mouse shown in A), with arrows indicating sites of viable and heat inactivated bacteria. C) Bioluminescent image of the mouse shown in A). D) ROI analysis from PET/CT scan of mice $(n=3) .{ }^{*}$ indicates statistical significance. doi:10.1371/journal.pone.0107951.g003

A

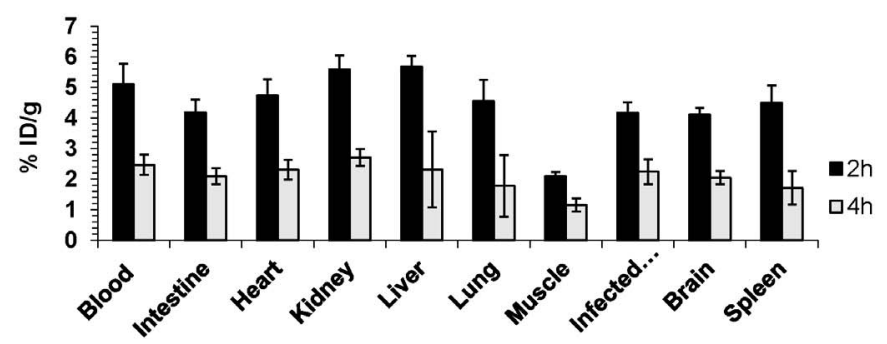

B

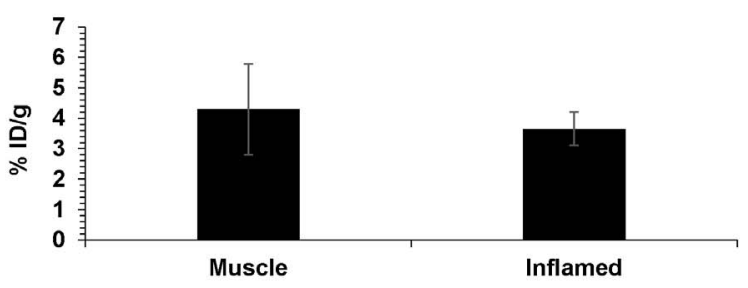

C

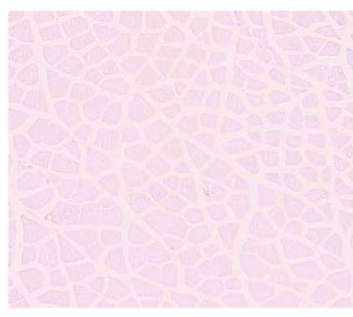

Control muscle

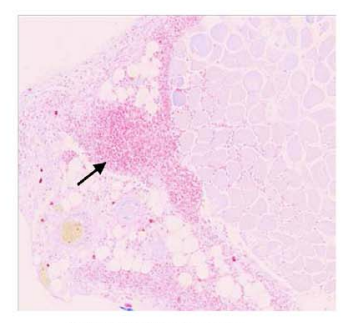

Infected muscle

D

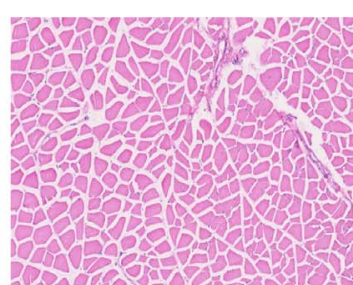

Control muscle

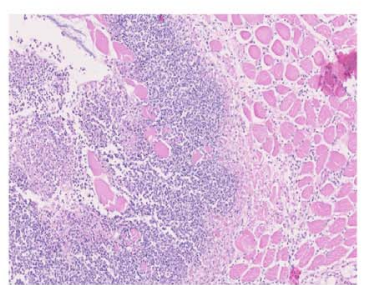

Inflamed muscle

Figure 4. Uptake of $6-\left[{ }^{18} \mathrm{~F}\right]$-fluoromaltose in infection versus inflammation. A) Ex-vivo biodistribution of 6 - $\left[{ }^{18} \mathrm{~F}\right]-$ fluoromaltose in mice bearing E.coli induced myositis, $2 \mathrm{~h}$ and $4 \mathrm{~h}$ after tail-vein injection of $7.4 \mathrm{MBq}$ of tracer. B) Ex-vivo biodistribution of $6-\left[{ }^{18} \mathrm{~F}\right]$-fluoromaltose in mice bearing turpentine oil induced sterile abscess, $2 \mathrm{~h}$ after tail-vein injection of 7.4MBq of tracer. C) Representative gram stained muscle sections with a black arrow indicating presence of E.coli in the infected muscle section. D) Representative H\&E stained muscle sections showing neutrophil infiltration in inflamed muscle.

doi:10.1371/journal.pone.0107951.g004 
${ }^{18} \mathrm{~F}$-labeled maltose derivatives, as evident from the high blood retention $(5 \% \mathrm{ID} / \mathrm{g}$, Fig. $4 \mathrm{~A})$ and the slow elimination from other organs including liver, kidneys and brain of our first generation tracer visualized using a dynamic PET/CT scan (Figure S3 in File $\mathrm{S} 1)$. We have evidence that this behavior might be related to the lack of complete trapping (and hence increased efflux) of $6-\left[{ }^{18} \mathrm{~F}\right]-$ fluoromaltose in E.coli cultures from cell culture studies (Figure $\mathrm{S} 4$ in File $\mathrm{S} 1)$. It is not clear yet if the $6-\left[{ }^{18} \mathrm{~F}\right]$-fluoromaltose is effluxed out of the bacteria as is or is partially metabolized in the bacteria into 6 - $\left[{ }^{18} \mathrm{~F}\right]$-fluoro-6 deoxy-glucose, which cannot also be trapped [20], and is subsequently transported out of the bacteria. Both of these scenarios would explain the relatively high levels of tracer in the blood pool.

In summary we have developed and tested a novel PET tracer, 6 - $\left[{ }^{18} \mathrm{~F}\right]$-fluoromaltose, that is taken up specifically by bacteria and only minimally taken up by mammalian cells. This specificity for bacterial cells would allow this class of probes to distinguish bacterial infection from inflammation,unlike $2^{\prime}-\left[{ }^{18} \mathrm{~F}\right]$ - Fluoro $2^{\prime}$ deoxyglucose (FDG), which is taken up in both conditions. This class of tracers would image both Gram-positive and Gramnegative bacterial populations including Pseudomonas aeruginosa, which has been notoriously difficult to image. There are other approaches to image specific classes of bacteria but there is a need to first develop a clinically relevant approach to image all bacterial infections, akin to FDG's role in clinical oncology. Although the 6$\left[{ }^{18} \mathrm{~F}\right]$-fluoromaltose does not completely fulfill these criteria because of its sub-optimal pharmacokinetics, the metabolism of maltose in man has been thoroughly investigated [21] and indicate that the pharmacokinetics of maltose based probes should be compatible with clinical development.

\section{Conclusions}

$6-\left[{ }^{18} \mathrm{~F}\right]$-fluoromaltose is a promising new tracer that has been evaluated for its ability to image and localize sites of bacterial infection. Our preliminary results in cell culture and in mice are encouraging and we are planning additional studies to evaluate the

\section{References}

1. Akhtar MS, Qaisar A, Irfanullah J, Iqbal J, Khan B, et al. (2005) Antimicrobial peptide ${ }^{99 \mathrm{~m}} \mathrm{Tc}$-ubiquicidin $29-41$ as human infection-imaging agent: clinical trial. J Nucl Med 46: 567-573.

2. Britton KE, Wareham DW, Das SS, Solanki KK, Amaral H, et al. (2002) Imaging bacterial infection with $\left({ }^{99 m}\right)$ Tc-ciprofloxacin (Infecton). J Clin Pathol 55: $817-823$.

3. Bunschoten A, Welling MM, Termaat MF, Sathekge M, van Leeuwen FW (2013) Development and prospects of dedicated tracers for the molecular imaging of bacterial infections. Bioconjug Chem 24: 1971-1989.

4. Machens HG, Pallua N, Becker M, Mailaender P, Schaller E, et al. (1996) Technetium- ${ }^{99 \mathrm{~m}}$ human immunoglobulin (HIG): a new substance for scintigraphic detection of bone and joint infections. Microsurgery 17: 272-277.

5. Sasser TA, Van Avermaete AE, White A, Chapman S, Johnson JR, et al. (2013) Bacterial infection probes and imaging strategies in clinical nuclear medicine and preclinical molecular imaging. Curr Top Med Chem 13: 479-487.

6. Hardy J, Francis KP, DeBoer M, Chu P, Gibbs K, et al. (2004) Extracellular replication of Listeria monocytogenes in the murine gall bladder. Science 303: 851-853.

7. Leevy WM, Serazin N, Smith BD (2007) Optical Imaging of Bacterial Infection Models. Drug Discov Today Dis Models 4: 91-97.

8. van Oosten M, Schafer T, Gazendam JA, Ohlsen K, Tsompanidou E, et al. (2013) Real-time in vivo imaging of invasive- and biomaterial-associated bacterial infections using fluorescently labelled vancomycin. Nat Commun 4: 2584.

9. Tang EN, Nair A, Baker DW, Hu W, Zhou J (2014) In vivo imaging of infection using a bacteria-targeting optical nanoprobe. J Biomed Nanotechnol 10: 856863.

10. Sachin K, Kim EM, Cheong SJ, Jeong HJ, Lim ST, et al. (2010) Synthesis of $\mathrm{N}(4)^{\prime}-\left[\left({ }^{18}\right) \mathrm{F}\right]$ fluoroalkylated ciprofloxacin as a potential bacterial infection imaging agent for PET study. Bioconjug Chem 21: 2282-2288. uptake of this class of tracers in a range of clinically relevant bacterial strains and murine models. These tracers will have potential impact in the clinical management of patients suspected of having bacterial infections. Determining the spread and extent of infection particularly in the case of patients admitted with wounds or with fever of unknown origin will help guide treatment protocols and reduce the morbidity and mortality associated with sepsis.

\section{Supporting Information}

File S1 Includes Figures S1-S4. Figure S1: 1 h uptake of ${ }^{3} \mathrm{H}-$ maltose in bacteria (E.coli) and a mammalian cell line (EL 4). Figure S2: A) Bioluminescent image of a mouse bearing $10^{6} \mathrm{CFU}$ of a bioluminescent strain of bacteria (see methods) on its right thigh B) A coronal slice from a micro PET/CT scan of the same mouse $1 \mathrm{~h}$ after administration of $7.4 \mathrm{MBq}$ of $6-\left[{ }^{18} \mathrm{~F}\right]$-fluoromaltose. Figure S3: Time activity curve for mice $(n=3)$ obtained from dynamic micro PET/CT showing distribution of $7.4 \mathrm{MBq}$ of 6 - $\left[{ }^{18} \mathrm{~F}\right]$-fluoromaltose in indicated organs. Figure S4: Plot showing $30 \mathrm{~min}$ uptake of $6-\left[{ }^{18} \mathrm{~F}\right]$-fluoromaltose in E.coli and residual activity observed at 30 minutes post efflux of tracer.

(DOCX)

Movie S1 Movie showing 3D color map from a PET/CT scan of a mouse bearing an E.coli infection on the left leg. The 3D projection also shows tracer accumulated in the liver, kidneys and bladder.

(MPG)

\section{Acknowledgments}

We acknowledge Dr. Frezghi Habte and the Stanford Small Animal Imaging Facility for help with the image analysis and quantitation. We are also grateful to the radiochemistry facility for radiochemistry support.

\section{Author Contributions}

Conceived and designed the experiments: GG SSG. Performed the experiments: GG MN EBJ RR AH. Analyzed the data: GG. Contributed reagents/materials/analysis tools: JH. Wrote the paper: GG AH SSG.

11. Diaz LA Jr., Foss CA, Thornton K, Nimmagadda S, Endres CJ, et al. (2007) Imaging of musculoskeletal bacterial infections by $\left[{ }^{124}\right.$ I]FIAU-PET/CT. PLoS One 2: e1007.

12. Peterson KL, Reid WC, Freeman AF, Holland SM, Pettigrew RI, et al. (2013) The use of ${ }^{14} \mathrm{C}-\mathrm{FIAU}$ to predict bacterial thymidine kinase presence: implications for radiolabeled FIAU bacterial imaging. Nucl Med Biol 40: 638-642.

13. Akhtar MS, Iqbal J, Khan MA, Irfanullah J, Jehangir M, et al. (2004) ${ }^{99 \mathrm{~m}} \mathrm{Tc}$ labeled antimicrobial peptide ubiquicidin (29-41) accumulates less in Escherichia coli infection than in Staphlococcus aureus infection. J Nucl Med 45: 849856.

14. Ning X, Lee S, Wang Z, Kim D, Stubblefield B, et al. (2011) Maltodextrin-based imaging probes detect bacteria in vivo with high sensitivity and specificity. Nat Mater 10: 602-607.

15. Ferenci $\mathrm{T}$ (1980) The recognition of maltodextrins by Escherichia coli. Eur J Biochem 108: 631-636.

16. Jones SA, Jorgensen M, Chowdhury FZ, Rodgers R, Hartline J, et al. (2008) Glycogen and maltose utilization by Escherichia coli O157:H7 in the mouse intestine. Infect Immun 76: 2531-2540.

17. Shelburne SA 3rd, Sumby P, Sitkiewicz I, Okorafor N, Granville C, et al. (2006) Maltodextrin utilization plays a key role in the ability of group A Streptococcus to colonize the oropharynx. Infect Immun 74: 4605-4614.

18. James ML, Gambhir SS (2012) A molecular imaging primer: modalities, imaging agents, and applications. Physiol Rev 92: 897-965.

19. Namavari M, Gowrishankar G, Hoehne A, Jouannot E, Gambhir SSSynthesis of $\left[{ }^{18 \mathrm{~F}}\right]$-labelled Maltose Derivatives as PET Tracers for Imaging Bacterial Infection Molecular Imaging and Biology.

20. Landau BR, Spring-Robinson CL, Muzic RF, Jr., Rachdaoui N, Rubin D, et al. (2007) 6-Fluoro-6-deoxy-D-glucose as a tracer of glucose transport. Am J Physiol Endocrinol Metab 293: E237-245.

21. Young JM, Weser E (1971) The metabolism of circulating maltose in man. J Clin Invest 50: 986-991. 